\section{OPEN ACCESS}

Edited by:

Aldo Corsetti,

Università di Teramo, Italy

Reviewed by:

Maria de los Angeles Serradell, Consejo Nacional de Investigaciones Cientificas y Técnicas (CONICET),

Argentina

Arun K. Bhunia,

Purdue University, United States

*Correspondence:

Gwénaël Jan

gwenael.jan@inra.fr

†These authors have contributed equally to this work

¥These authors share senior authorship.

Specialty section: This article was submitted to

Food Microbiology,

a section of the journal

Frontiers in Microbiology

Received: 15 December 2017

Accepted: 19 March 2018

Published: 04 April 2018

Citation

do Carmo FLR, Rabah H, De Oliveira Carvalho RD, Gaucher $F$ Cordeiro BF, da Silva SH, Le Loir Y, Azevedo $V$ and Jan $G(2018)$ Extractable Bacterial Surface Proteins in Probiotic-Host Interaction

Front. Microbiol. 9:645

doi: 10.3389/fmicb.2018.00645

\title{
Extractable Bacterial Surface Proteins in Probiotic-Host Interaction
}

\author{
Fillipe L. R. do Carmo 1,2t, Houem Rabah',3t, Rodrigo D. De Oliveira Carvalho', \\ Floriane Gaucher2,4, Barbara F. Cordeiro', Sara H. da Silva', Yves Le Loir'2, \\ Vasco Azevedo ${ }^{1 \neq}$ and Gwénaël Jan
}

1 Instituto de Ciências Biológicas, Universidade Federal de Minas Gerais (UFMG), Belo Horizonte, Brazil, ${ }^{2}$ STLO,

Agrocampus Ouest, INRA, Rennes, France, ${ }^{3}$ Pôle Agronomique Ouest, Rennes, France, ${ }^{4}$ Bioprox, Levallois-Perret, France

Some Gram-positive bacteria, including probiotic ones, are covered with an external proteinaceous layer called a surface-layer. Described as a paracrystalline layer and formed by the self-assembly of a surface-layer-protein (SIp), this optional structure is peculiar. The surface layer per se is conserved and encountered in many prokaryotes. However, the sequence of the corresponding Slp protein is highly variable among bacterial species, or even among strains of the same species. Other proteins, including surface layer associated proteins (SLAPS), and other non-covalently surface-bound proteins may also be extracted with this surface structure. They can be involved a various functions. In probiotic Gram-positives, they were shown by different authors and experimental approaches to play a role in key interactions with the host. Depending on the species, and sometime on the strain, they can be involved in stress tolerance, in survival within the host digestive tract, in adhesion to host cells or mucus, or in the modulation of intestinal inflammation. Future trends include the valorization of their properties in the formation of nanoparticles, coating and encapsulation, and in the development of new vaccines.

Keywords: surface layer protein, probiotic, immunomodulation, host, adhesion

\section{INTRODUCTION}

Probiotics are live microorganisms, traditionally regarded as safe for human consumption that, when ingested in sufficient numbers, confer a health benefit to the host (FAO/WHO, 2006). Probiotic microorganisms comprise mainly Gram-positive bacteria including LAB, bifidobacteria, enterococci, and propionibacteria. Some yeasts and Gram-negative bacteria may also be considered for probiotic use. Potential applications of probiotics involve the prevention and treatment of diarrhea caused by rotavirus, allergy and eczema, IBD; and the improvement of intestinal comfort, lactose intolerance, infection by Helicobacter pylori, and metabolic diseases (Syngai et al., 2016; Evivie et al., 2017). LAB constitute a large family of Gram-positive bacteria which are extensively implemented in the fermentation of a wide variety of food products. They include a variety

\footnotetext{
Abbreviations: APF, aggregation-promoting-like factor; CLR, C-type lectin receptor; CWBD, cell wall binding domain; DC, dendritic cell; DC-SIGN, dendritic cell-specific intercellular adhesion molecule-3-grabbing non-integrin; FAO, Food and Agriculture Organization; GALT, gut-associated lymphoid tissue; IBD, inflammatory bowel disease; IEC, intestinal epithelial cell; LAB, lactic acid bacteria; MAMP, microbe-associated molecular pattern; PBMC, peripheral blood mononuclear cell; PRR, pattern recognition receptor; SCWP, secondary cell-wall polymer; SLAP, S-layer associated protein; SLH, S-layer homology domain; Slp, surface-layer protein; TLR, toll-like receptor; WHO, World Health Organization.
} 
of probiotic species: Lactobacillus brevis, L. bulgaricus, L. plantarum, L. rhamnosus, L. casei, L. helveticus, L. salivarius, L. reuteri, L. johnsonii, L. fermentum, and L. acidophilus (AvallJääskeläinen and Palva, 2005). Propionibacteria, in particular Propionibacterium freudenreichii strains, are emergent probiotics, also used as ripening starter in Emmental cheese manufacturing, and as vitamins producers. These propionibacteria recently revealed potent beneficial effects, including the modulation of colon cancer cells proliferation and of colon inflammation (Rabah et al., 2017). Several molecular mechanisms behind these probiotics' beneficial effects are being elucidated. They involve modulation of the gut microbiota composition, stimulation of the epithelial barrier function, and induction of immune responses (Lebeer et al., 2008; Rabah et al., 2017). In addition, the role of bacterial surface compounds of Gram-positive bacteria includes the modulation of the gut immune system firstly, and then the systemic immune system, by mediating a cross-talk between the host and bacteria, whether they are commensals or probiotics. Such bacterial surface compounds constitute MAMPs; such as proteins, glycoproteins, lipoproteins, lipoteichoic acids, lipopolysaccharides and flagellins, which interact with the host PRRs, resulting in immune system modulation. Recently, several studies revealed the key role of surface-bound proteins, which are non-covalently attached to the cell wall, and are optionally present in certain probiotic bacteria. The surface-bound proteins may belong to a Slp lattice, an outermost macromolecular monolayer. First described in 1953 by Houwink, it consists of a paracrystalline bidimensional array made up of a Slp, which was first found on Spirillum sp. cell surface (Houwink, 1953; Sleytr et al., 2014). Slps are extracted using chaotropic agents such as guanidine chloride and lithium chloride (Koval and Murray, 1984). These agents may also extract other proteins, either associated to the S-layer lattice, or anchored to the cell wall through non-covalent interaction domains. These proteins include CWBDs, lysin motif domain (LysM), GW modules or SLH domains (Desvaux et al., 2006). Several studies revealed the involvement of surface-bound proteins in the bacteria/host interaction, leading to beneficial effects such as immune modulation, but the molecular mechanisms are still not fully understood. Indeed, they fulfill various crucial functions in bacteria, such as contribution to determination or maintenance of cell shape, molecular sieve, enzyme activities, contribution to adhesion, coaggregation, modulation of gut immune cells, protection against environmental stresses and antimicrobial peptides (Hynönen and Palva, 2013). The purpose of this review is to discuss involvement of non-covalently surface-bound proteins in Gram-positive probiotics' functionalities and thus in their beneficial effects, and their future biotechnological applications.

\section{OCCURRENCE, LOCATION, AND STRUCTURE OF S-LAYER PROTEINS}

\section{S-Layer Proteins}

S-layers are present in Archaea, Gram-positive and Gramnegative bacteria (Sára and Sleytr, 1996, 2000), they exhibit a thickness of 5-25 nm (Sára and Sleytr, 1996, 2000) and are highly porous (Sára and Sleytr, 1996; Sleytr and Beveridge, 1999). The S-layer paracrystalline lattice can be organized in different symmetry: oblique (p1, p2), tetragonal (p4), or hexagonal (p3, p6) symmetry (Lortal et al., 1993; Sleytr, 1997; Sleytr and Beveridge, 1999; Mobili et al., 2010). In Gram-positive bacteria, the S-layer lattice is generally composed of a single protein (Fagan and Fairweather, 2014; Pum and Sleytr, 2014; Sleytr et al., 2014), and is attached to peptidoglycan-bound SCWPs by non-covalent interactions (Fagan and Fairweather, 2014; Sleytr et al., 2014). The non-covalent anchorage of Slps may be mediated by different modules (Fagan and Fairweather, 2014). Three SLH domains can fold into a pseudo-trimer and cooperate in the binding to SCWPs. This is the most widely distributed anchorage of Slps, found in many Bacillus species and in the probiotic Propionibacterium freudenreichii (Le Maréchal et al., 2015). Another conserved anchorage mechanism is mediated via three modules of cellwall binding domain 2 (CWB2), found in many Clostridium species, and binding to cell wall compounds that are still not fully elucidated (Fagan and Fairweather, 2014). By contrast, Slps from members of the Lactobacillus species are devoid of such motif and are anchored by a conserved CWBD, which can be C-terminal (L. acidophilus, L. crispatus) or N-terminal (L. brevis), while the opposite part of the protein, more variable, is involved in the self-assembly (Hynönen and Palva, 2013). The L. acidophilus SlpA C-terminal binding domain, which represents one-third of the protein, interacts with negatively charged SCWPs and with neutral polysaccharides (Sleytr et al., 2014).

Slps possess a molecular weight ranging from 25 to $200 \mathrm{kDa}$ (Avall-Jääskeläinen and Palva, 2005) and are typically rich in acidic and hydrophobic amino acids (Sára and Sleytr, 1996, 2000; Sleytr and Beveridge, 1999; Pum and Sleytr, 2014), exhibiting a generally low isoelectric point (pI), with the exception of Lactobacillus Slps which have a high pI. In P. freudenreichii, five extractable surface proteins were identified using guanidine: SlpA, SlpB, SlpE, Internaline A (Inl A) and Large surface protein A (lsp A) (Le Maréchal et al., 2015; Deutsch et al., 2017). All these surface proteins are expressed quantitatively and qualitatively differently between different strains (Deutsch et al., 2017). However, only SlpA (illustrated in Figure 1) is considered as a true S-layer protein since its high expression level leads to the self-assembly of a SlpA-composed surface layer in P. freudenreichii strains CIRM-BIA 118 and CIRM-BIA 508 (alias CNRZ 722) (Lortal et al., 1993; de sa Peixoto et al., 2015). The SlpB protein, also presenting three SLH domains in its C-terminal domain (Figure 2), constitutes the major extractable surface protein in other $P$. freudenreichii strains, including CIRM BIA 129 (Le Maréchal et al., 2015). This suggests SlpB is a true S-layer protein, although the occurrence of a surface paracrystalline layer was not evidenced in these strains.

Glycosylation is the major covalent modification observed in Slps from Gram-positive bacteria. It was previously reported in L. kefiri and L. buchneri (Mobili et al., 2010). The glycosylation rate in Gram-positive bacteria Slps, leading to modification of 2-4 amino acid residues, is much lower than in Archaea. SlpB of L. buchneri shows four glycosylation sites consisting 

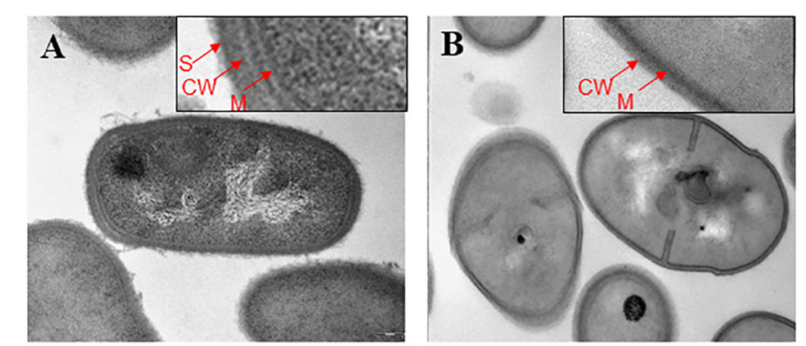

C
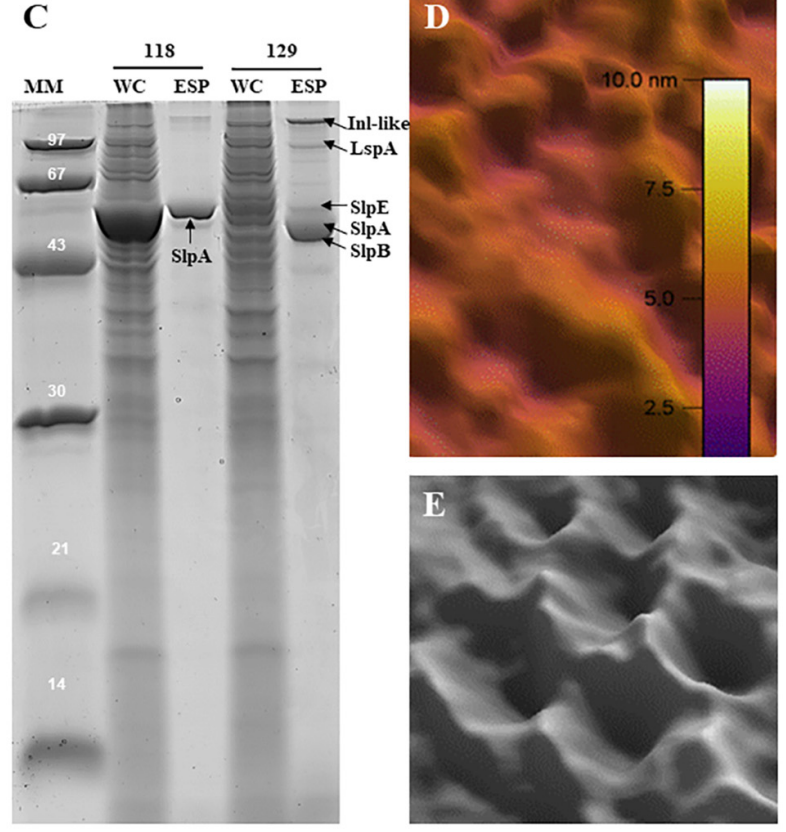

FIGURE 1 | Occurrence of an S-layer is strain-dependent in

Propionibacterium freudenreichii. P. freudenreichii CIRM-BIA 118 is covered by an outermost surface layer (A) that is removed by extraction using the chaotropic agent guanidine (B). Red arrows indicate the membrane (M), cell wall (CW), and S-layer (S). The CIRM-BIA 118 guanidine extract was analyzed by SDS-PAGE (C), showing a major band close to $58 \mathrm{kDa}$ corresponding to the S-layer protein A, as identified by MS/MS (Le Maréchal et al., 2015). Extracted SlpA was dialyzed against HEPES/ $\mathrm{NaCl}$ buffer and deposited on mica and recrystallized prior to atomic force microscopy imaging (de sa Peixoto et al., 2015). (D) Typical amplitude image obtained with purified SIp. (E) Close-up view of a Gaussian-filtered $40 \mathrm{~nm} \times 40 \mathrm{~nm}$ phase image of recrystallized Slp showing a hexagonal arrangement. By contrast,

P. freudenreichii CIRM-BIA 129 does not exhibit this S-layer (data not shown). However, extractable surface proteins (C), in this strain, include Inl-like protein, $145 \mathrm{kDa}$, LspA (96 kDa), SIpE (59 kDa), SlpA (58 kDa), and SIpB (56 kDa). MM, molecular mass markers; WC, whole-cell SDS protein extract; ESP, extractable surface proteins guanidine extract.

in O-glycosylation of seven glucose residues (Anzengruber et al., 2014). Slps glycosylations may be $N$ - or $O$-anchored to the peptide skeleton and consist in about 50 identical units containing neutral hexoses, pentoses, heptoses or deoxyhexose and amino sugars. The Slp of L. kefiri is O- and N-glycosylated, with 5-8 glucose units carrying galacturonic acid (Cavallero et al., 2017). Little is known about structure-function relationships of S-layer glycan moieties (Messner et al., 2008; Schuster and Sleytr, 2015). These covalent modifications, however, may be critical for the cross-talk between bacteria carrying Slps and the host through PRRs, as demonstrated for L. kefiri (Prado Acosta et al., 2016).

\section{Other Extractable Surface-Bound Proteins}

Being non-covalently anchored to the cell wall, surface-bound proteins are extracted from intact bacteria by the action of chaotropic agents such as lithium chloride and guanidine chloride. Thus, bacterial strains that do possess a true S-layer are characterized by the fact that extraction leads to the isolation of one single molecular protein species, able to re-assemble into a characteristic lattice. However, a thorough proteomic study of this extracted fraction evidenced other proteins, in addition to Slps, in L. acidophilus, for example, showing that Slps constitute an anchor for several other extractable surface-bound proteins called SLAPs (Johnson et al., 2013). Such proteins, identified in Lactobacillus species, have different functions, including interaction with the host (Johnson et al., 2013, 2016, 2017; Waśko et al., 2014; Zhang et al., 2016). In the absence of an S-layer, other non-covalently surface-bound proteins may exist and be extracted using chaotropic agents. They present different anchorage domains including SLH domains (Desvaux et al., 2006).

Surface proteome analysis of many $P$. freudenreichii strains revealed the presence of two other proteins, SlpE and Inl-like, a protein showing homology with InlA (internalin A), which exhibit C-terminal SLH domains, with a lower level of expression (Figures 1, 2). They are detected in strains with or without a true SlpA surface-layer, suggesting that they are not true Slps. Regarding the protein lspA (large surface protein A), it is predicted to have a mannosyl-glycoprotein endo-beta- $N$ acetylglucosamidase-like domain and no SLH domain. Similarly, several reports further evidenced extractable surface-bound proteins in probiotic lactobacilli, and designated them as Slps, based on the presence of SLH domains, although these proteins were not shown to constitute a true paracrystalline thick surface layer. These last were, however, taken into consideration on the present review, provided that they play a role in probiotic/host interaction.

\section{PROBIOTIC-HOST INTERACTION VIA EXTRACTABLE SURFACE PROTEINS}

The interaction between probiotic surface components and host cells may lead to modulation of gut functions (VelasquezManoff, 2015). Commensal bacteria colonizing the gut have co-evolved with their host and developed molecular interaction mechanisms involved in adherence, epithelial barrier function and in immune system development (Zaneveld et al., 2008; Vindigni et al., 2016). Therefore, immune cells and IECs are able to recognize several surface components (MAMPs) of autochthonous microbiota members, including lactobacilli and bifidobacteria, but also of allochthonous (food-borne) bacteria including lactobacilli, lactococci, and propionibacteria (Carvalho et al., 2017; Rook et al., 2017). The beneficial effect of probiotic bacteria, including activation of receptor-dependent pathways, 


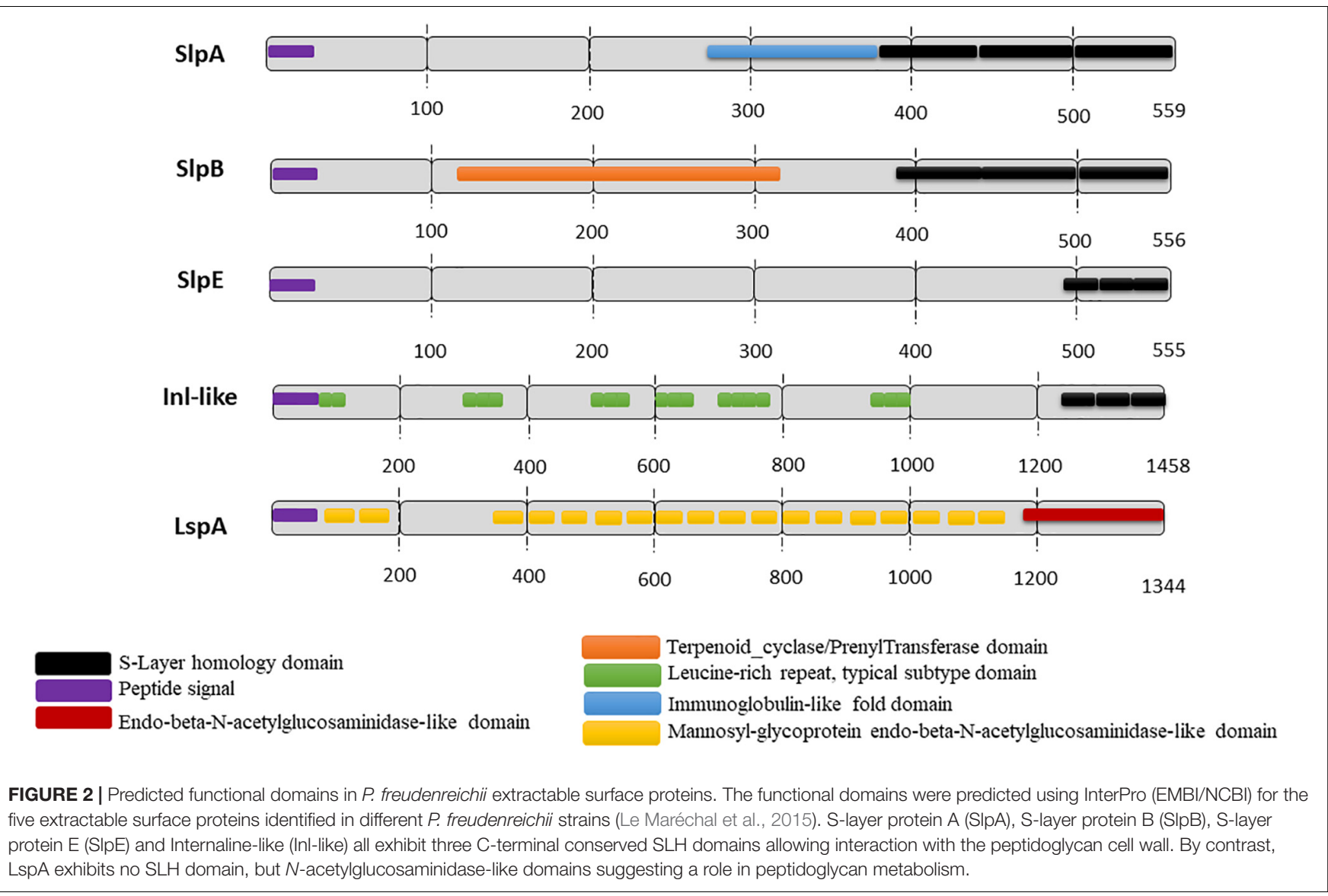

is most probably favored by its ability to adhere to target cells. In this context, PRRs, including TLRs, expressed by enterocytes, are able to recognize MAMP, including extractable surface proteins.

\section{Extractable Surface Proteins Are Involved in Adhesion to Epithelial Cells and Extracellular Matrix Proteins}

In order to exert a beneficial effect on the host, probiotic bacteria must have the ability to tolerate digestive stresses and interact with host cells [Food and Agriculture Organization of the United Nations and World Health Organization (FAO/WHO), 2002]. The adhesion of probiotic bacteria allows extending their persistence in the digestive tract, thus favoring a probiotic action. To understand how cell surface compounds from both partners can contribute to bacteria/cell adhesion, in vitro assays have been extensively used. This led to the development of recognized in vitro techniques (Blum et al., 1999; Vesterlund et al., 2005). This includes the use of IECs lines such as Caco-2 (Hirakata et al., 1998) and HT-29 (Maoret et al., 1989; Gagnon et al., 2013; Martínez-Maqueda et al., 2015). Extracellular components are also used for adhesion, including laminin, fibronectin, collagen, and proteoglycan. Intestinal mucus, an extracellular matrix composed of large glycoproteins (mucins), water, electrolyte, produced by goblet cells, may also be used. Extracellular components are reported to play a major role in modulating adhesion of microorganisms to epithelial surface (Otte and Podolsky, 2004; Johansson et al., 2011). Adhesion of probiotics to the gut mucosa may result in reduced colonization by pathogens, via competitive exclusion.

Several in vitro studies evidenced the involvement of extractable surface proteins, including Slps, in probiotic lactobacilli adhesion to mucus, and also to IECs. Gene inactivation of Slp genes was used in this purpose. Indeed, in Lactobacillus acidophilus NCFM, a knock-out mutant of the main S-layer protein, SlpA, evidenced its central role in adhesion to DCs and to their DC-SIGN receptors (Konstantinov et al., 2008). Inactivation of this gene also leads to reduced adhesion to cultured IEC (Buck et al., 2005). In the same strain, a key role of several surface layer associated proteins in adhesion was confirmed when the mutation of $A c m B$ ( $\beta$ - $N$-acetylglucosaminidase) (Johnson et al., 2016), and of APF (Goh and Klaenhammer, 2010), led to a reduced binding to mucin, laminin and collagen and to IECs. By contrast, the deletion of the SLAP Serine Protease Homolog PrtX in L. acidophilus NCFM increases adhesion to mucin and fibronectin, which may result from the liberation of binding sites from the S-layer proteinaceous matrix (Johnson et al., 2017). In $L$. salivarius REN, inactivation of $\operatorname{cbpA}$, encoding a SLAP choline-binding protein $\mathrm{A}$, showed reduced adhesion to cultured 
IEC (Wang et al., 2017). In other strains of L. acidophilus, the high expression of SIpA was correlated with a high capacity to adhere to Caco-2 cells (Ashida et al., 2011). However, it was reported that mutation of $s l p$ genes have pleiotropic effects, including the loss of exposure of a variety of SLAPs, making it difficult to conclude the specific role of each protein species.

A role of Slps in adhesion was also suggested by investigations using extracted surface proteins. Indeed, surface extractable proteins from L. acidophilus, L. brevis, L. helveticus, and L. kefiri block DC-SIGN receptors in vitro and prevent adhesion of pathogenic bacteria to DC-SIGN expressing cells (Prado Acosta et al., 2016). Furthermore, lithium extraction of L. acidophilus $\mathrm{fb} 214$ surface proteins reduces adhesion to cultured IECs (Meng et al., 2014). In L. acidophilus NCFM, $\mathrm{FbpB}$ is a SLAP, showing a fibronectin-binding domain, which mediates adhesion to mucin and fibronectin in vitro (Hymes et al., 2016). Accordingly, L. brevis ATCC 8287 surface layer shows a high affinity to laminin and to fibronectin, and its removal affects $L$. brevis adhesion to intestinal cells and to extracellular matrix proteins (Hynönen et al., 2002; de Leeuw et al., 2006; Uroić et al., 2016). Extracted surface bound proteins from probiotic lactobacilli were shown by different authors to bind in vitro to host cells proteins and extracellular matrix (Chen et al., 2007; Johnson-Henry et al., 2007; Carasi et al., 2014; Waśko et al., 2014; Prado Acosta et al., 2016; Zhang et al., 2016). However, such results should be considered with care, as Slps are poorly soluble, forming aggregates in aqueous environments, which renders interpretation of results difficult.

Adhesion to IECS and to mucus was also reported for dairy propionibacteria (Cousin et al., 2012). Nonetheless, the adhesion rates were highly variable, depending on the adhesion model used, the strain and the growth conditions (Cousin et al., 2010; Rabah et al., 2017). A comparative study of $P$. freudenreichii strains, in terms of 1) adhesion rate and 2) surface proteome, led to the identification of propionibacterial SlpB as a potent adhesin, which was further confirmed by $s l p b$ gene inactivation (de Carmo et al., 2017). One protein, Inl-like (Figure 2) contains several leucine-rich repeats (LRRs), predicted to be involved in protein binding. It shows homologies with InlA, which functions as an adhesin in Listeria monocytogenes. However, no functional characterization was undertaken to study the role of this protein in $P$. freudenreichii adhesion. Furthermore; the S-layer protein A of $P$. freudenreichii is predicted to have an Immunoglobulin-like fold domain, found in some surface proteins in pathogen bacteria (Buts et al., 2003; Lin et al., 2010), where it is reported to play a role in adhesion to host cells.

The in vitro investigations reported here indicate a role of Slps and other associated proteins in adhesion to mucus components and to IECs, which is a prominent feature for probiotic bacteria to trigger beneficial effects within the gut mucosa. Nonetheless, in vivo studies are needed to confirm the role of Slps in adhesion, and thus in the persistence of probiotic bacteria within the gut. In addition, Slps-mediated adhesion to mucus and IECs is poorly understood, but is thought to lead to inhibition of pathogenic microorganisms adhesion (Hynönen and Palva, 2013; Sleytr et al., 2014).

\section{Inhibition of Pathogens by Extractable Surface Proteins}

Inhibition of bacterial or viral infections is another beneficial application reported for probiotic bacteria, in which extractable surface proteins may play an important role. Indeed, adhesion of probiotic bacteria to the intestinal mucosa, via surface extractable adhesins interacting with host PRRs, may result in the inhibition of pathogens invasion by competitive exclusion. As an example, L. helveticus R0052 inhibits adhesion of entero-hemorrhagic Escherichia coli to caco-2 cells and so does its lithium surface proteins extract (Johnson-Henry et al., 2007), which coaggregates with several pathogen species (Beganović et al., 2011; Waśko et al., 2014). In addition, Slps of L. crispatus ZJ001 (Chen et al., 2007), L. kefir (Golowczyc et al., 2007), L. salivarius, and L. reuteri (Zhang et al., 2013) were proposed to be responsible for competitive exclusion of bacterial pathogens such as E. coli and Salmonella species. A similar effect was shown for L. acidophilus Slps which inhibited adherence and invasion of Caco-2 cells by Salmonella enterica serovar Typhimurium (Li et al., 2010, 2011) and protected cells by restoring the transepithelial resistance. This resistance is a recognized marker of barrier integrity of tight junctions, in epithelial cell lines (Klingberg et al., 2005). These Slps inhibited the mitogen-activated protein kinase (MAPK) signaling pathways induced by $S$. typhimurium (Li et al., 2011). In the same way, L. plantarum CGMCC 1258 MIMP protein, an extractable surface protein, limits pathogen invasion by inducing the expression of Claudin-1, Occludin, JAM-1, and ZO-1, by restoring tight junction damage and thus epithelium integrity (Qin et al., 2009; Liu et al., 2011a,b). Indeed, the intestinal mucosa tightness, relying on tight junctions (or "zonula occludens"), is impaired in several inflammatory and infections gut diseases (Vélez et al., 2007; Sengupta et al., 2013).

A potential role of extractable surface proteins covering L. acidophilus ATCC4356, L. brevis ATCC14869, L. helveticus ATCC12046 or L. kefiri JCM5818 against bacterial infection of cells was observed (Prado Acosta et al., 2016). Cells expressing the DC-specific DC-SIGN receptor exhibited a reduced susceptibility to bacterial infections, as a result of pre-treatment with Lactobacilli Slps. Moreover, pre-treatment of the pathogens (both Gram-negative and mycobacterial models) with Slps from L. acidophilus ATCC 4356 and L. brevis ATCC 14869 reduces pathogens viability but also prevents infection (Prado Acosta et al., 2016). DC-SIGN is a CLR present in DCs and macrophages, it is involved in the recognition of several viruses and other microbes, a key step in the entry of pathogens into the cell. Indeed, L. acidophilus ATCC4356 Slps stimulate the activation of mouse DCs by activating IFN-I signaling pathway, which inhibit invasion of DCs by influenza virus H9N2 (Gao et al., 2016). In addition, L. acidophilus ATCC4356 Slps inhibit the Junin virus (JUNV) infection by interacting with DC-SIGN (Martínez et al., 2012).

These data suggest a role of probiotics extractable surface proteins, including Slps, in the prevention of host colonization 
by pathogens responsible for infectious diarrhea. Once again, data obtained using extracted surface bound proteins should be considered with care and these hypotheses should be confirmed in vivo.

\section{Immunomodulatory Properties of Extractable Surface Proteins}

Selected strains of LAB, including $L$. acidophilus, and of PROPIONIBACTERIA, including $P$. freudenreichii, exert anti-inflammatory properties in the context of colitis, by modulating gut immunity. Intestinal homeostasis is tightly governed by regulatory immune mechanisms, which are established by interactions involving commensal/probiotic bacteria and host PRRs, including CLRs and TLRs. The disruption of such regulatory mechanisms may result in IBD. Figure 3A illustrates the cross-talk between probiotic bacteria and the host, mediated by IECs and immunes cells within the GALT, which initiates an immune responses according to the MAMPs recognized by various PRRs. This hypothetical schema is mainly based on in vitro investigations.

Detailed studies revealed the crucial role of Slps in host-probiotic interactions mediated by intestinal cells,
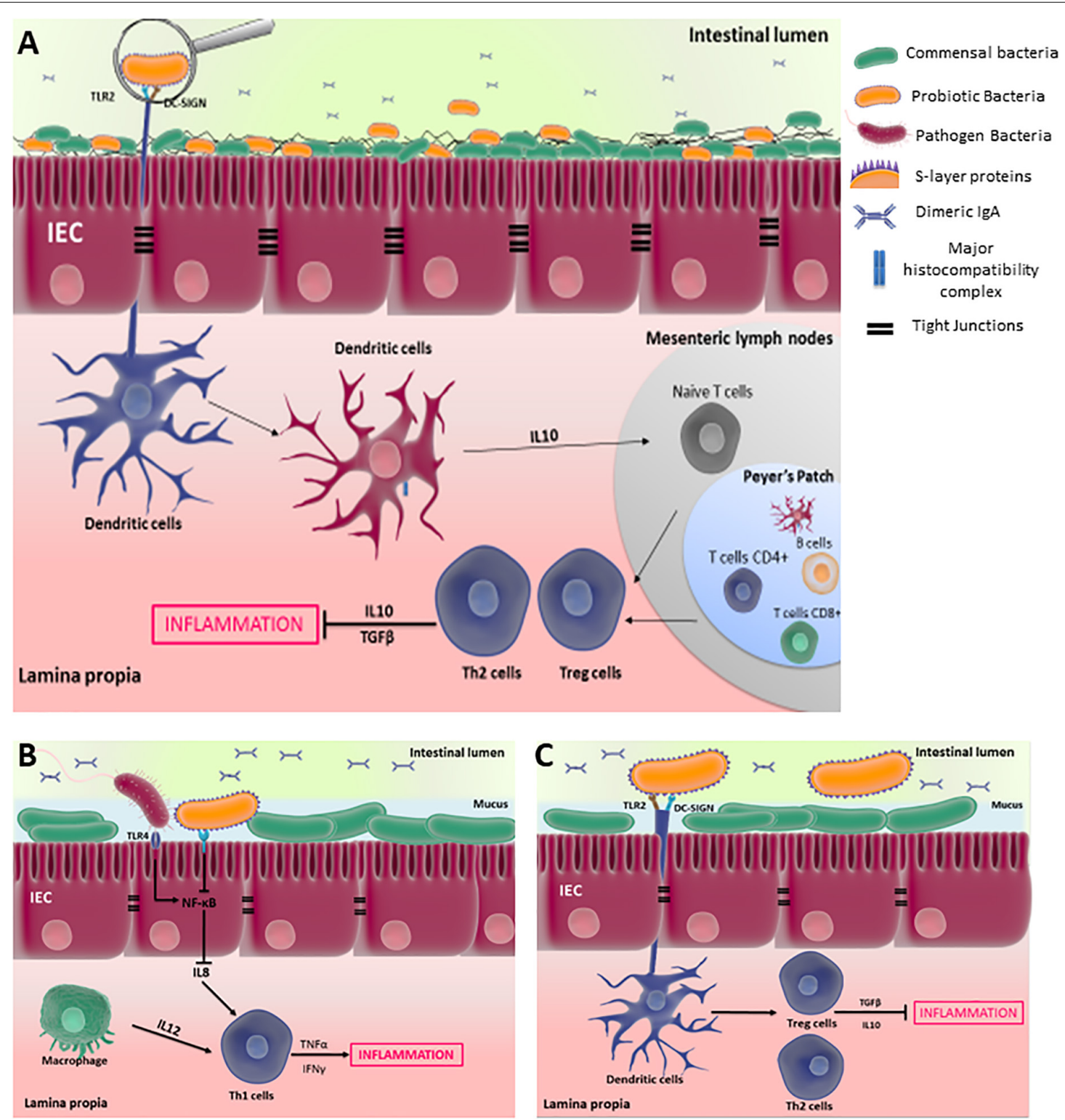

FIGURE 3 | Cross-talk between probiotic bacteria and the host, mediated by IECs and immunes cells, within the gut associated lymphoid tissues (GALT). (A) An overview of the interaction of antigen-presenting-cells such as DCs with probiotic bacterian, which initiates a tolerance response by inducing Treg/Th2 anti-inflammatory response; while DCs-pathogenic bacteria interaction induces a Th1/Th17 proinflammatory response. (B) S-layer proteins inhibit the proinflammatory response of epithelial cells by reducing NF-kB activity, which is induced by pathogenic bacteria; (C) S-layer proteins are recognized by DCs via DC-SIGN and TLR2 receptors, inducing tolerance response in the GALT. These hypothetical schemata are mainly based on in vitro investigations. 
which are an important protagonist at the forefront to maintain gut immunity homeostasis. L. helveticus MIMLh5 anti-inflammatory effects on Caco- 2 cells is mediated by its SlpA and reduces activation of NF-кB (Taverniti et al., 2013). L. acidophilus contains three different Slps, SlpA, SlpB, and SlpX, which interact with PRRs and modulate the immune response. L. acidophilus Slps decrease interleukin (IL) 8 secretion in Caco-2 cells stimulated by S. typhimurium (Li et al., 2011). IL-8 cytokine is an important proinflammatory mediator secreted by intestinal cells, as well as by activated macrophages, leading, in synergy with IL-12, to the development of T helper (Th1) cells in the intestinal mucosa (Sanchez-Muñoz et al., 2008). Figure 3B illustrates how probiotics, via the recognition of Slps, may reduce activation of NF- $\mathrm{B}$ and therefore expression of IL8 in IECs, limiting the proinflammatory response induced by pathogen.

Besides the interaction with IECs, Slps interact with antigen-presenting cells such as DCs, which reside in the Peyer's patch, lamina propria and mesenteric lymph nodes. As schematized in Figure 3A, DCs are the main stimulators of naive $\mathrm{T}$ cells, which distinguishes them from all other antigen presenting cells. Depending on the microbial stimulus encountered, DCs promote the differentiation of naïve $\mathrm{T}$ cells toward Th1, Th2, unpolarized $\mathrm{T}$ cells, Th17 or $\mathrm{T}$ regulatory cell responses. Investigation of the role of L. acidophilus Slps provided insights into immune cells-Slps interactions and the resulting immune response within the gut. The high expression of SlpA in L. acidophilus L92 was correlated with high induction of IL-12p70 secretion during splenocytes stimulation (Ashida et al., 2011). However, SlpA of L. acidophilus was reported to confer anti-inflammatory traits to the strain. Indeed, mutation of L. acidophilus NCFM SlpA results in a chromosomal inversion leading to dominant expression of SlpB. This mutant induces higher levels of proinflammatory cytokines such as IL-12p70, tumor necrosis factor- $\alpha$ (TNF $\alpha)$, and IL-1, compared to the wild-type strain, in DCs. However, both SlpA and SIpB activated TLR-2 at similar levels, an interaction that appeared to be crucial for the activating of IL-4-producing $\mathrm{T}$ cells (Konstantinov et al., 2008). The protective role of SlpA in the context of colitis was further elucidated. L. acidophilus NCK2187, which solely expresses SlpA, and its purified SlpA, both bind to the $\mathrm{C}$-type lectin SIGNR3 to induce regulatory signals that result in alleviation of colitis (Lightfoot et al., 2015). However, such protection was not observed in Signr3-/mice, suggesting that the SlpA/SIGNR3 interaction plays a key regulatory role in the healing of colitis (Lightfoot et al., 2015). Other extractable surface proteins are involved in L. acidophilus NCFM immunomodulatory properties (Johnson et al., 2013, 2017). Indeed, mutation of the S-layer-associated serine protease homolog (Prtx) in L. acidophilus NCFM enhanced stimulation of IL-6, IL-12, and IL-10, compared to wild-type, when exposed to mouse DCs (Johnson et al., 2017). The authors suggest that PrtX may degrade certain cytokines, so that amounts of cytokines are higher when using the mutant. Mutation of Lba-1029, a putative SLAP in L. acidophilus NCFM, revealed its role in a pro-inflammatory response in murine DCs, including $\mathrm{TNF} \alpha$ secretion (Johnson et al., 2013). SLAPs may thus take part in probiotics immunological properties. Slps of L. helveticus NS8, isolated from fermented koumiss, had no effect on the basal production of IL-10 in mouse macrophage cell line RAW264.7, but decreased IL12 expression triggered by LPS stimulation, suggesting an anti-inflammatory potential (Rong et al., 2015). Lactobacilli Slps contribute to the anti-inflammatory effect of probiotic bacteria within GALT, by interacting with DCs via different PRRs, which initiate the differentiation of Treg cells as illustrated by Figure 3C. Contrastingly, L. helveticus MIMLh5 and its SlpA act as stimulators of the innate immune system by triggering the expression of proinflammatory mediators such as $\mathrm{TNF} \alpha$ and cyclooxygenase 2 (COX-2) in the human macrophage cell line U937 via TLR2 recognition (Taverniti et al., 2013). In the same experiments, this purified SlpA did not affect the expression of the anti-inflammatory cytokine interleukin-10 (Taverniti et al., 2013). Similarly, L. brevis Slps induce TNF $\alpha$ production in monocyte-derived dendritic cells (moDCs) (Uroić et al., 2016).

Immunomodulation was also reported for PROPIONIBACTERIA. As an example, strain-dependent immunomodulatory properties were evidenced in vitro using human PBMCs (Foligné et al., 2013; Deutsch et al., 2017) and then confirmed in vivo in a mouse colitis model (Foligné et al., 2010). Extractable surface proteins were involved in this modulatory effect (Le Maréchal et al., 2015). Indeed, the extracted proteins induce regulatory IL-10, in a dose-dependent manner, in PBMCs, with little or no secretion of pro-inflammatory factors (IL-12, TNF $\alpha$, and IL6) (Le Maréchal et al., 2015). In addition, they reduce the proinflammatory response triggered by the proinflammatory strain Lactococcus lactis MG1363 in PBMCs (Le Maréchal et al., 2015). Inactivation of the gene encoding SlpB suppress IL-10 induction by P. freudenreichii, and so does inactivation of SlpE (Deutsch et al., 2017). In the same time, expression of other surface proteins, including SlpF and moonlighting proteins, is also correlated with this anti-inflammatory trait in $P$. freudenreichii. By contrast, P. freudenreichii strains expressing high level of SlpA, a true S-layer protein, exert no immunomodulatory effect. The authors suggest that the immunomodulatory properties of $P$. freudenreichii strains result from a combination of several surface proteins (Deutsch et al., 2017). By contrast with lactobacilli, mechanisms involved in the interaction between PRRs and PROPIONIBACTERIA surface proteins remain unknown.

In conclusion, probiotic bacteria, via Slps, may have an immunomodulatory effect mediated by C-type lectin and TLR receptors within GALT. However, the effective role of these proteins should be confirmed in vivo in order to give tools to fight gut inflammation.

\section{PROTECTIVE ROLE OF PROBIOTICS' EXTRACTABLE SURFACE PROTEINS}

Bacterial surface layers are generally recognized as the outermost structure of the bacterial cell (Gerbino et al., 2015a). They are thus widely considered to play a key role as an interface between intra- and extra-cellular compartments, and thus between the 
bacterium and its environment or its host. This interface was most likely developed as a consequence of the selective pressure generated by these interactions. They may act as a physical barrier against external factors (Sleytr and Messner, 1988), and also prevent the release of cellular molecules (Sleytr and Messner, 1988). Indeed, they are described as a molecular sieve, forming a highly porous structure with pores exhibiting identical morphology and size, within a bacterial strain, with some variations among strains. The porosity of this layer occupies a surface area that can go up to 70\% (Sleytr et al., 2001; AvallJääskeläinen and Palva, 2005). Studies on permeability have shown that some S-layers prevent the entry of molecules with molecular weights exceeding $10,000-15,000 \mathrm{kDa}$, providing the strain with a selective advantage (Lortal et al., 1993).

The presence of surface layers was reportedly linked with enhanced tolerance toward stresses. Presence of an S-layer was reported to decrease $L$. helveticus susceptibility to mutanolysin (Lortal et al., 1992). S-layers were furthermore shown to resist to extreme environmental conditions, even in extremophile bacteria, and to digestive assaults including variations in $\mathrm{pH}$, bile salts, proteases and simulated gastrointestinal conditions (Smit et al., 2001; Chen et al., 2007; Eslami et al., 2013). In accordance, coating of liposomes with S-layer proteins from L. brevis and from L. kefiri increased their stability upon exposure to bile salts, pancreatic extract and $\mathrm{pH}$, as compared to uncoated liposomes (Hollmann et al., 2007). On the other hand, removal of Slps caused enhanced L. hilgardii susceptibility toward bacteriolytic enzymes and physicochemical stress (Dohm et al., 2011). Furthermore, removal of the surface layer using the chaotropic agent lithium chloride drastically affects survival of $L$. acidophilus and of $L$. helveticus in simulated gastric and intestinal conditions (Frece et al., 2005; Meng et al., 2014). In accordance with a physiological role of S-layer proteins in defense mechanisms, their expression is induced by stimuli participating in digestive stress. In L. acidophilus, exposition to bile increases expression of SlpA in the ATCC 4356 strain (Khaleghi et al., 2010). The same authors further evidenced similar induction of this protein by acidic $\mathrm{pH}$ and heat stress (Khaleghi and Kasra, 2012). Among bile constituents, bile salts were further evidenced as the stimuli responsible for S-layer induction in L. acidophilus IBB 8001 (Grosu-Tudor et al., 2016). The induction of Slps expression may thus take part in a general strategy to adapt and survive harsh environmental conditions encountered in the environment, in the digestive tract, or in the succession thereof (Butler et al., 2013; Gerbino et al., 2015a). However, contrasting informations result from experimental gene inactivation of S-layer proteins in probiotic bacteria. Such mutations were indeed reported to drastically affect interactions with the host, including adhesion (do Carmo et al., 2017; Wang et al., 2017) and immune modulation (Konstantinov et al., 2008; Deutsch et al., 2017). However, their impact on probiotics stress tolerance is still elusive. Deletion of the slpa gene caused alterations in cell envelope structure and defect in resistance to solvent and shear stresses in the environmental extremophilic bacterium Deinococcus radiodurans (Rothfuss et al., 2006). In the probiotic L. acidophilus, the auxiliary S-layer protein SlpX, identified as a protein associated with the S-layer complex, plays a role in its permeability. Indeed, inactivation of SlpX affects the growth rate and the tolerance to bile salts in the NCK1962 mutant, as well as its relative overexpression in NCK1377, a SlpBdominant strain that lacks SlpA protein. The NCK1962 slpXnegative mutant is more susceptible to SDS, yet more resistant to bile, than the wild type (Goh et al., 2009). Aggregationpromoting factors (Apf) are proteins considered as "S-layer-like" and identified at the surface of several lactobacilli. They share several characteristics with Lactobacillus S-layer proteins, such as their relative abundance on the cell surface, extractability by lithium chloride ( $\mathrm{LiCl}$ ), amino acid composition, predicted physical properties like high $\mathrm{pI}$ and indispensability for growth (Ventura et al., 2002; Jankovic et al., 2003). Mutation of the corresponding apf gene in L. acidophilus resulted in enhanced susceptibility to SDS, to bile and to intestinal and gastric juices (Goh and Klaenhammer, 2010). This suggests reduced survival during transit through the digestive tract.

Finally, S-layers may also play a role in detoxification. The biosorption of toxic compounds, including uranium (Hennig et al., 2001) and heavy metals (Velásquez and Dussan, 2009) was reported for telluric bacteria belonging to the Bacillus species. It was attributed to their S-layers (Merroun et al., 2005). Such heavy metal biosorption was later reported for L. kefir (Gerbino et al., 2015b) with a key role of S-layer proteins. Biosorption of heavy metals and of mycotoxins was reported in L. rhamnosus and in P. freudenreichii (Ibrahim et al., 2006; Halttunen et al., 2008). These last were shown in a clinical study to reduce the biologically effective dose of aflatoxin exposure and may thereby offer an effective dietary approach to decrease the risk of liver cancer (El-Nezami et al., 2006).

\section{BIOTECHNOLOGICAL APPLICATIONS}

The peculiar property of Slps to auto-assemble and to form reproducible supramolecular aggregates that are reputed irreversible and resistant to physicochemical assaults naturally led to the idea to use them in the field of (nano)biotechnology (Hynönen et al., 2002; Sleytr et al., 2011). Such monomolecular arrays provide well-defined structures, depending on the physicochemical properties of the glycoprotein, which constitutes the closed, isoporous lattice, and for which a wide biodiversity exists, among bacteria. This led to investigate the application of re-crystalized Slps to develop ultrafiltration membranes with very accurate molecular cutoffs, good stability afforded by intramolecular cross-linking, low membrane fouling and tunable surface properties in terms of net charges and hydrophilicity. Furthermore, chemical modifications and genetic engineering allow the immobilization of functional molecules, including enzymes, ligands, antigens and antibodies, while retaining the self-assembly properties of Slps. Some Slps being known to spontaneously produce preformed nanoparticles, on native surface-layers, functionalized Slps nanoparticles were made, including metallic and semiconductor nanoparticles. Other applications include Slps as supporting structures for functional lipid membranes, or for vaccine development. Indeed, conjugate vaccines with Slps and antigens, haptens or recombinant 
allergens, gave promising results in vaccination trials, due to intrinsic adjuvant properties of some SlpS. For a review on Slps biotechnological applications, se the review by Sleytr et al. (2014).

\section{CONCLUSION}

Extractable surface proteins, with various properties, have been described in several species and strains of probiotic bacteria. The peculiar properties of extractable surface proteins, including abundant expression, self-assembly, surface location, resistance to physicochemical assaults, immunomodulation, adhesion and toxic remediation, offer the possibility to orientate the biological properties of fermented food products and of probiotic food supplements. S-layer proteins have a great potential in the field of nanobiotechnology, because of their ability to form repetitive protein arrays by spontaneous association (Hynönen et al., 2002; Sleytr et al., 2011). This applies to vaccine candidates, to surface display of epitope, of proteins with therapeutic or biotechnologic interest (Michon et al., 2016). This opens promising perspectives in the field of gut disorders, including IBS and IBD, infectious diseases, as well as oral vaccination. Future trends include engineering of Slps for specific, efficient and cost-effective

\section{REFERENCES}

Anzengruber, J., Pabst, M., Neumann, L., Sekot, G., Heinl, S., Grabherr, R., et al. (2014). Protein O-glucosylation in Lactobacillus buchneri. Glycoconj. J. 31, 117-131. doi: 10.1007/s10719-013-9505-7

Ashida, N., Yanagihara, S., Shinoda, T., and Yamamoto, N. (2011). Characterization of adhesive molecule with affinity to Caco-2 cells in Lactobacillus acidophilus by proteome analysis. J. Biosci. Bioeng. 112, 333-337. doi: 10.1016/j.jbiosc.2011. 06.001

Avall-Jääskeläinen, S., and Palva, A. (2005). Lactobacillus surface layers and their applications. FEMS Microbiol. Rev. 29, 511-529. doi: 10.1016/j.femsre.2005. 04.003

Beganović, J., Frece, J., Kos, B., Leboš Pavunc, A., Habjanič, K., and Sušković, J. (2011). Functionality of the S-layer protein from the probiotic strain Lactobacillus helveticus M92. Antonie Van Leeuwenhoek 100, 43-53. doi: 10.1007/s10482-011-9563-4

Blum, S., Reniero, R., Schiffrin, E. J., Crittenden, R., Mattila-Sandholm, T., Ouwehand, A. C., et al. (1999). Adhesion studies for probiotics: need for validation and refinement. Trends Food Sci. Technol. 10, 405-410. doi: 10.1016/ S0924-2244(00)00028-5

Buck, B. L., Altermann, E., Svingerud, T., and Klaenhammer, T. R. (2005). Functional analysis of putative adhesion factors in Lactobacillus acidophilus NCFM. Appl. Environ. Microbiol. 71, 8344-8351. doi: 10.1128/AEM.71.12. 8344-8351.2005

Butler, È., Alsterfjord, M., Olofsson, T. C., Karlsson, C., Malmström, J., and Vásquez, A. (2013). Proteins of novel lactic acid bacteria from Apis mellifera mellifera: an insight into the production of known extra-cellular proteins during microbial stress. BMC Microbiol. 13:235. doi: 10.1186/1471-2180-13-235

Buts, L., Bouckaert, J., De Genst, E., Loris, R., Oscarson, S., Lahmann, M., et al. (2003). The fimbrial adhesin F17-G of enterotoxigenic Escherichia coli has an immunoglobulin-like lectin domain that binds $\mathrm{N}$-acetylglucosamine. Mol. Microbiol. 49, 705-715.

Carasi, P., Ambrosis, N. M., De Antoni, G. L., Bressollier, P., Urdaci, M. C., and Serradell, M. L. Á. (2014). Adhesion properties of potentially probiotic Lactobacillus kefiri to gastrointestinal mucus. J. Dairy Res. 81, 16-23. doi: 10.1017/S0022029913000526 targeting of desired antigens and other medically important molecules.

\section{AUTHOR CONTRIBUTIONS}

GJ, YLL, and VA supervised the work and corrected the manuscript. FLRdC and HR did the main part of the bibliographical survey. All the authors took part in the writing of the manuscript.

\section{FUNDING}

This work was supported by Conselho Nacional de Desenvolvimento Científico e Tecnológico (CNPq, Brazil). HR is the recipient of a doctoral fellowship from Bba, FG from Bioprox.

\section{ACKNOWLEDGMENTS}

The authors thank Fanny Guyomarc'h, Julien Jardin, Sacha Vroux, and Roch Ford for the useful discussions and advice. They also thank Alan Jan and Jeannette Alexis Arresla for scientific and English proof-reading.

Carvalho, R. D., Breyner, N., Menezes-Garcia, Z., Rodrigues, N. M., Lemos, L., Maioli, T. U., et al. (2017). Secretion of biologically active pancreatitis-associated protein I (PAP) by genetically modified dairy Lactococcus lactis NZ9000 in the prevention of intestinal mucositis. Microb. Cell Fact. 16:27. doi: 10.1186/s12934-017-0624-x

Cavallero, G. J., Malamud, M., Casabuono, A. C., Serradell, M. L. Á., and Couto, A. S. (2017). A glycoproteomic approach reveals that the S-layer glycoprotein of Lactobacillus kefiri CIDCA 83111 is O- and N-glycosylated. J. Proteomics 162, 20-29. doi: 10.1016/j.jprot.2017.04.007

Chen, X., Xu, J., Shuai, J., Chen, J., Zhang, Z., and Fang, W. (2007). The S-layer proteins of Lactobacillus crispatus strain ZJ001 is responsible for competitive exclusion against Escherichia coli O157:H7 and Salmonella typhimurium. Int. J. Food Microbiol. 115, 307-312. doi: 10.1016/j.ijfoodmicro.2006.11.007

Cousin, F. J., Deutsch, S.-M., Perez Chaia, A., Foligné, B., and Jan, G. (2012). Interactions between probiotic dairy propionibacteria and the intestinal epithelium. Curr. Immunol. Rev. 8, 216-226. doi: 10.2174/15733951280067 1976

Cousin, F. J., Mater, D. D. G., Foligné, B., and Jan, G. (2010). Dairy propionibacteria as human probiotics: a review of recent evidence. Dairy Sci. Technol. 91, 1-26. doi: $10.1051 / \mathrm{dst} / 2010032$

de Leeuw, E., Li, X., and Lu, W. (2006). Binding characteristics of the Lactobacillus brevis ATCC 8287 surface layer to extracellular matrix proteins. FEMS Microbiol. Lett. 260, 210-215. doi: 10.1111/j.1574-6968.2006.00313.x

de sa Peixoto, P., Roiland, C., Thomas, D., Briard-Bion, V., Le Guellec, R., Parayre, S., et al. (2015). Recrystallized S-layer protein of a probiotic propionibacterium: structural and nanomechanical changes upon temperature or pH shifts probed by solid-state NMR and AFM. Langmuir 31, 199-208. doi: 10.1021/la503735z

Desvaux, M., Dumas, E., Chafsey, I., and Hébraud, M. (2006). Protein cell surface display in Gram-positive bacteria: from single protein to macromolecular protein structure. FEMS Microbiol. Lett. 256, 1-15. doi: 10.1111/j.1574-6968. 2006.00122.x

Deutsch, S.-M., Mariadassou, M., Nicolas, P., Parayre, S., Le Guellec, R., Chuat, V., et al. (2017). Identification of proteins involved in the anti-inflammatory properties of Propionibacterium freudenreichii by means of a multi-strain study. Sci. Rep. 7:46409. doi: 10.1038/srep46409 
de Carmo, F. L. R., Rabah, H., Huang, S., Gaucher, F., Deplanche, M., Dutertre, S., et al. (2017). Propionibacterium freudenreichii surface protein SlpB is involved in adhesion to intestinal HT-29 cells. Front. Microbiol. 8:1033. doi: 10.3389/ fmicb.2017.01033

do Carmo, F. L. R., Rabah, H., Huang, S., Gaucher, F., Deplanche, M., Dutertre, S., et al. (2017). Propionibacterium freudenreichii surface protein SlpB is involved in adhesion to intestinal HT-29 cells. Front. Microbiol. 8:1033. doi: 10.3389/ fmicb.2017.01033

Dohm, N., Petri, A., Schlander, M., Schlott, B., König, H., and Claus, H. (2011). Molecular and biochemical properties of the S-layer protein from the wine bacterium Lactobacillus hilgardii B706. Arch. Microbiol. 193, 251-261. doi: 10.1007/s00203-010-0670-9

El-Nezami, H. S., Polychronaki, N. N., Ma, J., Zhu, H., Ling, W., Salminen, E. K., et al. (2006). Probiotic supplementation reduces a biomarker for increased risk of liver cancer in young men from Southern China. Am. J. Clin. Nutr. 83, 1199-1203.

Eslami, N., Kermanshahi, R. K., and Erfan, M. (2013). Studying the stability of S-layer protein of Lactobacillus acidophilus ATCC 4356 in simulated gastrointestinal fluids using SDS-PAGE and circular dichroism. Iran. J. Pharm. Res. 12, 47-56.

Evivie, S. E., Huo, G.-C., Igene, J. O., and Bian, X. (2017). Some current applications, limitations and future perspectives of lactic acid bacteria as probiotics. Food Nutr. Res. 61:1318034. doi: 10.1080/16546628.2017.1318034

Fagan, R. P., and Fairweather, N. F. (2014). Biogenesis and functions of bacterial S-layers. Nat. Rev. Microbiol. 12, 211-222. doi: 10.1038/nrmicro3213

FAO/WHO (2006). Probiotics in Food: Health and Nutritional Properties and Guidelines for Evaluation. Report of a Joint FAO/WHO Working Group on Drafting Guidelines for the Evaluation of Probiotics in Food. Rome: FAO.

Foligné, B., Breton, J., Mater, D., and Jan, G. (2013). Tracking the microbiome functionality: focus on Propionibacterium species. Gut 62, 1227-1228. doi: 10.1136/gutjnl-2012-304393

Foligné, B., Deutsch, S.-M., Breton, J., Cousin, F. J., Dewulf, J., Samson, M., et al. (2010). Promising immunomodulatory effects of selected strains of dairy propionibacteria as evidenced in vitro and in vivo. Appl. Environ. Microbiol. 76, 8259-8264. doi: 10.1128/AEM.01976-10

Food and Agriculture Organization of the United Nations, and World Health Organization (FAO/WHO) (ed.) (2002). Probiotics in Food: Health and Nutritional Properties and Guidelines for Evaluation. Rome: Food and Agriculture Organization of the United Nations.

Frece, J., Kos, B., Svetec, I. K., Zgaga, Z., Mrsa, V., and Suskovic, J. (2005). Importance of S-layer proteins in probiotic activity of Lactobacillus acidophilus M92. J. Appl. Microbiol. 98, 285-292.

Gagnon, M., Zihler Berner, A., Chervet, N., Chassard, C., and Lacroix, C. (2013). Comparison of the Caco-2, HT-29 and the mucus-secreting HT29-MTX intestinal cell models to investigate Salmonella adhesion and invasion. J. Microbiol. Methods 94, 274-279. doi: 10.1016/j.mimet.2013.06.027

Gao, X., Huang, L., Zhu, L., Mou, C., Hou, Q., and Yu, Q. (2016). Inhibition of H9N2 virus invasion into dendritic cells by the S-Layer protein from L. acidophilus ATCC 4356. Front. Cell. Infect. Microbiol. 6:137. doi: 10.3389/ fcimb.2016.00137

Gerbino, E., Carasi, P., Mobili, P., Serradell, M. A., and Gómez-Zavaglia, A. (2015a). Role of S-layer proteins in bacteria. World J. Microbiol. Biotechnol. 31, 1877-1887. doi: 10.1007/s11274-015-1952-9

Gerbino, E., Carasi, P., Araujo-Andrade, C., Tymczyszyn, E. E., and GómezZavaglia, A. (2015b). Role of S-layer proteins in the biosorption capacity of lead by Lactobacillus kefir. World J. Microbiol. Biotechnol. 31, 583-592. doi: 10.1007/s11274-015-1812-7

Goh, Y. J., Azcarate-Peril, M. A., O’Flaherty, S., Durmaz, E., Valence, F., Jardin, J., et al. (2009). Development and application of an upp-based counterselective gene replacement system for the study of the S-layer protein SlpX of Lactobacillus acidophilus NCFM. Appl. Environ. Microbiol. 75, 3093-3105. doi: 10.1128/AEM.02502-08

Goh, Y. J., and Klaenhammer, T. R. (2010). Functional roles of aggregationpromoting-like factor in stress tolerance and adherence of Lactobacillus acidophilus NCFM. Appl. Environ. Microbiol. 76, 5005-5012. doi: 10.1128/ AEM.00030-10

Golowczyc, M. A., Mobili, P., Garrote, G. L., Abraham, A. G., and De Antoni, G. L. (2007). Protective action of Lactobacillus kefir carrying S-layer protein against
Salmonella enterica serovar Enteritidis. Int. J. Food Microbiol. 118, 264-273. doi: 10.1016/j.ijfoodmicro.2007.07.042

Grosu-Tudor, S.-S., Brown, L., Hebert, E. M., Brezeanu, A., Brinzan, A., Fadda, S., et al. (2016). S-layer production by Lactobacillus acidophilus IBB 801 under environmental stress conditions. Appl. Microbiol. Biotechnol. 100, 4573-4583. doi: 10.1007/s00253-016-7355-5

Halttunen, T., Collado, M. C., El-Nezami, H., Meriluoto, J., and Salminen, S. (2008). Combining strains of lactic acid bacteria may reduce their toxin and heavy metal removal efficiency from aqueous solution. Lett. Appl. Microbiol. 46, 160-165. doi: 10.1111/j.1472-765X.2007.02276.x

Hennig, C., Panak, P. J., Reich, T., Rossberg, A., Raff, J., Selenska-Pobell, S., et al. (2001). EXAFS investigation of uranium (VI) complexes formed at Bacillus cereus and Bacillus sphaericus surfaces. Radiochim. Acta 89, 625-631.

Hirakata, Y., Izumikawa, K., Yamaguchi, T., Igimi, S., Furuya, N., Maesaki, S., et al. (1998). Adherence to and penetration of human intestinal Caco-2 epithelial cell monolayers by Pseudomonas aeruginosa. Infect. Immun. 66, 1748-1751.

Hollmann, A., Delfederico, L., Glikmann, G., De Antoni, G., Semorile, L., and Disalvo, E. A. (2007). Characterization of liposomes coated with S-layer proteins from lactobacilli. Biochim. Biophys. Acta 1768, 393-400. doi: 10.1016/ j.bbamem.2006.09.009

Houwink, A. L. (1953). A macromolecular mono-layer in the cell wall of Spirillum spec. Biochim. Biophys. Acta 10, 360-366.

Hymes, J. P., Johnson, B. R., Barrangou, R., and Klaenhammer, T. R. (2016). Functional analysis of an S-layer-associated fibronectin-binding protein in Lactobacillus acidophilus NCFM. Appl. Environ. Microbiol. 82, 2676-2685. doi: 10.1128/AEM.00024-16

Hynönen, U., and Palva, A. (2013). Lactobacillus surface layer proteins: structure, function and applications. Appl. Microbiol. Biotechnol. 97, 5225-5243. doi: 10.1007/s00253-013-4962-2

Hynönen, U., Westerlund-Wikström, B., Palva, A., and Korhonen, T. K. (2002). Identification by flagellum display of an epithelial cell- and fibronectin-binding function in the SlpA surface protein of Lactobacillus brevis. J. Bacteriol. 184, 3360-3367.

Ibrahim, F., Halttunen, T., Tahvonen, R., and Salminen, S. (2006). Probiotic bacteria as potential detoxification tools: assessing their heavy metal binding isotherms. Can. J. Microbiol. 52, 877-885.

Jankovic, I., Ventura, M., Meylan, V., Rouvet, M., Elli, M., and Zink, R. (2003). Contribution of aggregation-promoting factor to maintenance of cell shape in Lactobacillus gasseri 4B2. J. Bacteriol. 185, 3288-3296.

Johansson, M. E. V., Ambort, D., Pelaseyed, T., Schütte, A., Gustafsson, J. K., Ermund, A., et al. (2011). Composition and functional role of the mucus layers in the intestine. Cell. Mol. Life Sci. 68, 3635-3641. doi: 10.1007/s00018-0110822-3

Johnson, B., Selle, K., O'Flaherty, S., Goh, Y. J., and Klaenhammer, T. (2013). Identification of extracellular surface-layer associated proteins in Lactobacillus acidophilus NCFM. Microbiology 159, 2269-2282. doi: 10.1099/mic.0.070755-0

Johnson, B. R., Hymes, J., Sanozky-Dawes, R., Henriksen, E. D., Barrangou, R., and Klaenhammer, T. R. (2016). Conserved S-layer-associated proteins revealed by exoproteomic survey of S-layer-forming lactobacilli. Appl. Environ. Microbiol. 82, 134-145. doi: 10.1128/AEM.01968-15

Johnson, B. R., O'Flaherty, S., Goh, Y. J., Carroll, I., Barrangou, R., and Klaenhammer, T. R. (2017). The S-layer associated serine protease homolog PrtX impacts cell surface-mediated microbe-host interactions of Lactobacillus acidophilus NCFM. Front. Microbiol. 8:1185. doi: 10.3389/fmicb.2017.01185

Johnson-Henry, K. C., Hagen, K. E., Gordonpour, M., Tompkins, T. A., and Sherman, P. M. (2007). Surface-layer protein extracts from Lactobacillus helveticus inhibit enterohaemorrhagic Escherichia coli O157:H7 adhesion to epithelial cells. Cell. Microbiol. 9, 356-367. doi: 10.1111/j.1462-5822.2006. 00791.x

Khaleghi, M., and Kasra, R. (2012). "Effect of environmental stresses on S-Layer production in Lactobacillus acidophilus ATCC 4356," in Advances in Applied Biotechnology, ed. M. Petre (Rijeka: InTech).

Khaleghi, M., Kermanshahi, R. K., Yaghoobi, M. M., Zarkesh-Esfahani, S. H., and Baghizadeh, A. (2010). Assessment of bile salt effects on S-layer production, slp gene expression and some physicochemical properties of Lactobacillus acidophilus ATCC 4356. J. Microbiol. Biotechnol. 20, 749-756.

Klingberg, T. D., Pedersen, M. H., Cencic, A., and Budde, B. B. (2005). Application of Measurements of transepithelial electrical resistance of intestinal epithelial 
cell monolayers to evaluate probiotic activity. Appl. Environ. Microbiol. 71, 7528-7530. doi: 10.1128/AEM.71.11.7528-7530.2005

Konstantinov, S. R., Smidt, H., de Vos, W. M., Bruijns, S. C. M., Singh, S. K., Valence, F., et al. (2008). S-layer protein A of Lactobacillus acidophilus NCFM regulates immature dendritic cell and T cell functions. Proc. Natl. Acad. Sci. U.S.A. 105, 19474-19479. doi: 10.1073/pnas.0810305105

Koval, S. F., and Murray, R. G. (1984). The isolation of surface array proteins from bacteria. Can. J. Biochem. Cell Biol. Rev. Can. Biochim. Biol. Cell. 62, 1181-1189.

Le Maréchal, C., Peton, V., Plé, C., Vroland, C., Jardin, J., Briard-Bion, V., et al. (2015). Surface proteins of Propionibacterium freudenreichii are involved in its anti-inflammatory properties. J. Proteomics 113, 447-461. doi: 10.1016/j.jprot. 2014.07.018

Lebeer, S., Vanderleyden, J., and De Keersmaecker, S. C. J. (2008). Genes and molecules of lactobacilli supporting probiotic action. Microbiol. Mol. Biol. Rev. 72, 728-764. doi: 10.1128/MMBR.00017-08

Li, P., Ye, X., Wang, Z., Yu, Q., and Yang, Q. (2010). Effects of S-layer proteins from Lactobacillus against Salmonella typhimurium adhesion and invasion on Caco-2 cells. Wei Sheng Wu Xue Bao 50, 1226-1231.

Li, P., Yu, Q., Ye, X., Wang, Z., and Yang, Q. (2011). Lactobacillus S-layer protein inhibition of Salmonella-induced reorganization of the cytoskeleton and activation of MAPK signalling pathways in Caco-2 cells. Microbiol. Read. Engl. 157, 2639-2646. doi: 10.1099/mic.0.049148-0

Lightfoot, Y. L., Selle, K., Yang, T., Goh, Y. J., Sahay, B., Zadeh, M., et al. (2015). SIGNR3-dependent immune regulation by Lactobacillus acidophilus surface layer protein A in colitis. EMBO J. 34, 881-895. doi: 10.15252/embj.201490296

Lin, Y.-P., McDonough, S. P., Sharma, Y., and Chang, Y.-F. (2010). The terminal immunoglobulin-like repeats of LigA and LigB of Leptospira enhance their binding to gelatin binding domain of fibronectin and host cells. PLoS One 5:e11301. doi: 10.1371/journal.pone.0011301

Liu, Z., Shen, T., Chen, H., Zhou, Y., Zhang, P., Ma, Y., et al. (2011a). Functional characterization of MIMP for its adhesion to the intestinal epithelium. Front. Biosci. 16:2106-2127.

Liu, Z., Shen, T., Zhang, P., Ma, Y., and Qin, H. (2011b). Lactobacillus plantarum surface layer adhesive protein protects intestinal epithelial cells against tight junction injury induced by enteropathogenic Escherichia coli. Mol. Biol. Rep. 38, 3471-3480. doi: 10.1007/s11033-010-0457-8

Lortal, S., Rouault, A., Cesselin, B., and Sleytr, U. B. (1993). Paracrystalline surface layers of dairy propionibacteria. Appl. Environ. Microbiol. 59, 2369-2374.

Lortal, S., Van Heijenoort, J., Gruber, K., and Sleytr, U. B. (1992). S-layer of Lactobacillus helveticus ATCC 12046: isolation chemical characterization and re-formation after extraction with lithium chloride. J. Gen. Microbiol. 138, 611-618.

Maoret, J. J., Font, J., Augeron, C., Codogno, P., Bauvy, C., Aubery, M., et al. (1989). A mucus-secreting human colonic cancer cell line. Purification and partial characterization of the secreted mucins. Biochem. J. 258, 793-799. doi: $10.1042 / b j 2580793$

Martínez, M. G., Prado Acosta, M., Candurra, N. A., and Ruzal, S. M. (2012). S-layer proteins of Lactobacillus acidophilus inhibits JUNV infection. Biochem. Biophys. Res. Commun. 422, 590-595. doi: 10.1016/j.bbrc.2012.05.031

Martínez-Maqueda, D., Miralles, B., and Recio, I. (2015). "HT29 cell line," in The Impact of Food Bioactives on Health, eds K. Verhoeckx, P. Cotter, I. LópezExpósito, C. Kleiveland, T. Lea, and A. Mackie (Cham: Springer International Publishing), 113-124. doi: 10.1007/978-3-319-16104-4_11

Meng, J., Zhu, X., Gao, S.-M., Zhang, Q.-X., Sun, Z., and Lu, R.-R. (2014). Characterization of surface layer proteins and its role in probiotic properties of three Lactobacillus strains. Int. J. Biol. Macromol. 65, 110-114. doi: 10.1016/ j.ijbiomac.2014.01.024

Merroun, M. L., Raff, J., Rossberg, A., Hennig, C., Reich, T., and SelenskaPobell, S. (2005). Complexation of uranium by cells and S-layer sheets of Bacillus sphaericus JG-A12. Appl. Environ. Microbiol. 71, 5532-5543. doi: 10.1128/AEM.71.9.5532-5543.2005

Messner, P., Steiner, K., Zarschler, K., and Schäffer, C. (2008). S-layer nanoglycobiology of bacteria. Carbohydr. Res. 343, 1934-1951. doi: 10.1016/j. carres.2007.12.025

Michon, C., Langella, P., Eijsink, V. G. H., Mathiesen, G., and Chatel, J. M. (2016). Display of recombinant proteins at the surface of lactic acid bacteria: strategies and applications. Microb. Cell Fact. 15:70. doi: 10.1186/s12934-016$0468-9$
Mobili, P., Gerbino, E., Tymczyszyn, E., and Gómez-Zavaglia, A. (2010). S-layers in lactobacilli: structural characteristics and putative role in surface and probiotic properties of whole bacteria. Curr. Res. Technol. Educ. Top. Appl. Microbiol. Microb. Biotechnol. 22, 1224-1234.

Otte, J.-M., and Podolsky, D. K. (2004). Functional modulation of enterocytes by gram-positive and gram-negative microorganisms. Am. J. Physiol. Gastrointest. Liver Physiol. 286, G613-G626. doi: 10.1152/ajpgi.00341.2003

Prado Acosta, M., Ruzal, S. M., and Cordo, S. M. (2016). S-layer proteins from Lactobacillus sp. inhibit bacterial infection by blockage of DC-SIGN cell receptor. Int. J. Biol. Macromol. 92, 998-1005. doi: 10.1016/j.ijbiomac.2016. 07.096

Pum, D., and Sleytr, U. B. (2014). Reassembly of S-layer proteins. Nanotechnology 25:312001. doi: $10.1088 / 0957-4484 / 25 / 31 / 312001$

Qin, H., Zhang, Z., Hang, X., and Jiang, Y. (2009). L. plantarum prevents enteroinvasive Escherichia coli-induced tight junction proteins changes in intestinal epithelial cells. BMC Microbiol. 9:63. doi: 10.1186/1471-21809-63

Rabah, H., Rosa do Carmo, F. L., and Jan, G. (2017). Dairy propionibacteria: versatile probiotics. Microorganisms 5:E24. doi: 10.3390/ microorganisms5020024

Rong, J., Zheng, H., Liu, M., Hu, X., Wang, T., Zhang, X., et al. (2015). Probiotic and anti-inflammatory attributes of an isolate Lactobacillus helveticus NS8 from Mongolian fermented koumiss. BMC Microbiol. 15:196. doi: 10.1186/s12866015-0525-2

Rook, G., Bäckhed, F., Levin, B. R., McFall-Ngai, M. J., and McLean, A. R. (2017). Evolution, human-microbe interactions, and life history plasticity. Lancet 390, 521-530. doi: 10.1016/S0140-6736(17)30566-4

Rothfuss, H., Lara, J. C., Schmid, A. K., and Lidstrom, M. E. (2006). Involvement of the S-layer proteins Hpi and SlpA in the maintenance of cell envelope integrity in Deinococcus radiodurans R1. Microbiol. Read. Engl. 152, 2779-2787. doi: 10.1099/mic.0.28971-0

Sanchez-Muñoz, F., Dominguez-Lopez, A., and Yamamoto-Furusho, J. K. (2008). Role of cytokines in inflammatory bowel disease. World J. Gastroenterol. 14, 4280-4288. doi: 10.3748/wjg.14.4280

Sára, M., and Sleytr, U. B. (1996). Crystalline bacterial cell surface layers (S-layers): from cell structure to biomimetics. Prog. Biophys. Mol. Biol. 65, 83-111. doi: 10.1016/S0079-6107(96)00007-7

Sára, M., and Sleytr, U. B. (2000). S-Layer proteins. J. Bacteriol. 182, 859-868.

Schuster, B., and Sleytr, U. B. (2015). Relevance of glycosylation of S-layer proteins for cell surface properties. Acta Biomater. 19, 149-157. doi: 10.1016/j.actbio. 2015.03.020

Sengupta, R., Altermann, E., Anderson, R. C., McNabb, W. C., Moughan, P. J., and Roy, N. C. (2013). The role of cell surface architecture of lactobacilli in host-microbe interactions in the gastrointestinal tract. Mediators Inflamm. 2013:237921. doi: 10.1155/2013/237921

Sleytr, U. B. (1997). I. Basic and applied S-layer research: an overview. FEMS Microbiol. Rev. 20, 5-12. doi: 10.1111/j.1574-6976.1997.tb00301.x

Sleytr, U. B., and Beveridge, T. J. (1999). Bacterial S-layers. Trends Microbiol. 7, 253-260.

Sleytr, U. B., and Messner, P. (1988). Crystalline surface layers in procaryotes. J. Bacteriol. 170, 2891-2897.

Sleytr, U. B., Sára, M., Pum, D., and Schuster, B. (2001). Characterization and use of crystalline bacterial cell surface layers. Prog. Surf. Sci. 68, 231-278. doi: 10.1016/S0079-6816(01)00008-9

Sleytr, U. B., Schuster, B., Egelseer, E.-M., and Pum, D. (2014). S-layers: principles and applications. FEMS Microbiol. Rev. 38, 823-864. doi: 10.1111/1574-6976. 12063

Sleytr, U. B., Schuster, B., Egelseer, E. M., Pum, D., Horejs, C. M., Tscheliessnig, R., et al. (2011). Nanobiotechnology with S-layer proteins as building blocks. Prog. Mol. Biol. Transl. Sci. 103, 277-352. doi: 10.1016/B978-0-12-415906-8.00 003-0

Smit, E., Oling, F., Demel, R., Martinez, B., and Pouwels, P. H. (2001). The S-layer protein of Lactobacillus acidophilus ATCC 4356: identification and characterization of domains responsible for S-protein assembly and cell wall binding. J. Mol. Biol. 305, 245-257. doi: 10.1006/jmbi.2000.4258

Syngai, G. G., Gopi, R., Bharali, R., Dey, S., Lakshmanan, G. M. A., and Ahmed, G. (2016). Probiotics - the versatile functional food ingredients. J. Food Sci. Technol. 53, 921-933. doi: 10.1007/s13197-015-2011-0 
Taverniti, V., Stuknyte, M., Minuzzo, M., Arioli, S., De Noni, I., Scabiosi, C., et al. (2013). S-layer protein mediates the stimulatory effect of Lactobacillus helveticus MIMLh5 on innate immunity. Appl. Environ. Microbiol. 79, 1221-1231. doi: 10.1128/AEM.03056-12

Uroić, K., Novak, J., Hynönen, U., Pietilä, T. E., Leboš Pavunc, A., Kant, R., et al. (2016). The role of S-layer in adhesive and immunomodulating properties of probiotic starter culture Lactobacillus brevis D6 isolated from artisanal smoked fresh cheese. Food Sci. Technol. 69, 623-632. doi: 10.1016/j.lwt.2016.02.013

Velásquez, L., and Dussan, J. (2009). Biosorption and bioaccumulation of heavy metals on dead and living biomass of Bacillus sphaericus. J. Hazard. Mater. 167, 713-716. doi: 10.1016/j.jhazmat.2009.01.044

Velasquez-Manoff, M. (2015). Gut microbiome: the peacekeepers. Nature 518, S3-S11. doi: 10.1038/518S3a

Vélez, M. P., De Keersmaecker, S. C. J., and Vanderleyden, J. (2007). Adherence factors of Lactobacillus in the human gastrointestinal tract. FEMS Microbiol. Lett. 276, 140-148. doi: 10.1111/j.1574-6968.2007.00908.x

Ventura, M., Jankovic, I., Walker, D. C., Pridmore, R. D., and Zink, R. (2002). Identification and characterization of novel surface proteins in Lactobacillus johnsonii and Lactobacillus gasseri. Appl. Environ. Microbiol. 68, 6172-6181.

Vesterlund, S., Paltta, J., Karp, M., and Ouwehand, A. C. (2005). Measurement of bacterial adhesion-in vitro evaluation of different methods. J. Microbiol. Methods 60, 225-233. doi: 10.1016/j.mimet.2004.09.013

Vindigni, S. M., Zisman, T. L., Suskind, D. L., and Damman, C. J. (2016). The intestinal microbiome, barrier function, and immune system in inflammatory bowel disease: a tripartite pathophysiological circuit with implications for new therapeutic directions. Ther. Adv. Gastroenterol. 9, 606-625. doi: 10.1177/ $1756283 \mathrm{X} 16644242$
Wang, R., Jiang, L., Zhang, M., Zhao, L., Hao, Y., Guo, H., et al. (2017). The Adhesion of Lactobacillus salivarius REN to a Human intestinal epithelial cell line requires S-layer proteins. Sci. Rep. 7:44029. doi: 10.1038/srep44029

Waśko, A., Polak-Berecka, M., Paduch, R., and Jóźwiak, K. (2014). The effect of moonlighting proteins on the adhesion and aggregation ability of Lactobacillus helveticus. Anaerobe 30C, 161-168. doi: 10.1016/j.anaerobe.2014.10.002

Zaneveld, J., Turnbaugh, P. J., Lozupone, C., Ley, R. E., Hamady, M., Gordon, J. I., et al. (2008). Host-bacterial coevolution and the search for new drug targets. Curr. Opin. Chem. Biol. 12, 109-114. doi: 10.1016/j.cbpa.2008.01.015

Zhang, W., Wang, H., Liu, J., Zhao, Y., Gao, K., and Zhang, J. (2013). Adhesive ability means inhibition activities for Lactobacillus against pathogens and S-layer protein plays an important role in adhesion. Anaerobe 22, 97-103. doi: 10.1016/j.anaerobe.2013.06.005

Zhang, Y., Xiang, X., Lu, Q., Zhang, L., Ma, F., and Wang, L. (2016). Adhesions of extracellular surface-layer associated proteins in Lactobacillus M5-L and Q8-L. J. Dairy Sci. 99, 1011-1018. doi: 10.3168/jds.2015-10020

Conflict of Interest Statement: The authors declare that the research was conducted in the absence of any commercial or financial relationships that could be construed as a potential conflict of interest.

Copyright (c) 2018 do Carmo, Rabah, De Oliveira Carvalho, Gaucher, Cordeiro, da Silva, Le Loir, Azevedo and Jan. This is an open-access article distributed under the terms of the Creative Commons Attribution License (CC BY). The use, distribution or reproduction in other forums is permitted, provided the original author(s) and the copyright owner are credited and that the original publication in this journal is cited, in accordance with accepted academic practice. No use, distribution or reproduction is permitted which does not comply with these terms. 